\title{
P-1069 Characteristics and perceptions of barriers to diabetes education of healthcare professionals in Thailand
}

Lukana Preechasuk ${ }^{1}$, Pornsri Sriussadaporn ${ }^{1}$, Supawadee Likitmaskul ${ }^{1,2}$

Siriraj Diabetes Center ${ }^{1}$, Division of Endocrine and Metabolism, Department of Pediatric ${ }^{2}$ Faculty of Medicine Siriraj Hospital, Mahidol University, Thailand

Mahidol University Faculty of Medicine Siriraj Hospital

\section{Background}

Diabetes education is integral to successful diabetes management. However, data about characteristics and barriers of diabetes education in clinical practice in Thailand is limited.

\section{Objectives}

To describe characteristics of diabetes education and identify perceptions of barriers to diabetes education among administrators, doctors and other healthcare professionals working as diabetes educators (DEs) in Thailand.

\section{Method}

A survey was conducted in 613 hospitals (508 public and 105 private hospitals) across Thailand from December 2016 to March 2017. A self-completion questionnaire was sent to administrators, diabetes clinic doctors, and health professionals working as a DE to collect data about the workload, characteristics of diabetes education from DEs and perceived barriers to diabetes education from 3 groups of respondents.

\section{Result (1)}

The overall response rate was $54.8 \%$ (58.3\% public and $38 \%$ private hospitals). The response rate of administrators, doctors and DEs was $48.3 \%, 49.9 \%$ and $65.7 \%$, respectively.

The median (IQR) number of DEs per hospital was 4 $(2,6)$. The median (IQR) number of patients per educator per week was higher in public hospitals than private hospitals $(70[30,150]$ vs. $20[10,30])$.

Table 1. Characteristics of diabetes education programs in public and private hospitals

\begin{tabular}{|c|c|c|}
\hline & $\begin{array}{c}\text { Public } \\
\text { hospitals }\end{array}$ & $\begin{array}{c}\text { Private } \\
\text { hospitals }\end{array}$ \\
\hline \multicolumn{3}{|l|}{ Criteria to provide DM education, $\mathrm{n}(\%)$} \\
\hline Newly diagnosed diabetes & $332(93.5)$ & $34(70.8)$ \\
\hline Uncontrolled diabetes & $310(87.3)$ & $23(47.9)$ \\
\hline \multicolumn{3}{|l|}{ Defined as } \\
\hline Fasting plasma glucose & 183 & 150 \\
\hline$(\mathrm{mg} / \mathrm{dL})$ & $(180,200)$ & $(128,180)$ \\
\hline HbA1c (\%) & $8(7,8)$ & $7(7,8)$ \\
\hline Diabetes with complication & $225(63.4)$ & $21(43.8)$ \\
\hline \multicolumn{3}{|l|}{ Method of DM education, $\mathrm{n}(\%)$} \\
\hline Individual education & $339(95.5)$ & $37(77.1)$ \\
\hline Group education & $282(79.4)$ & $14(29.2)$ \\
\hline \multicolumn{3}{|l|}{ Duration of DM education session } \\
\hline Individual education (min/ session) & $15(10,30)$ & $30(12.5,30)$ \\
\hline Group education (min/ session) & $30(20,30)$ & $30(25,60)$ \\
\hline \multicolumn{3}{|l|}{ Evaluation of DM education, $n(\%)$} \\
\hline Successful & $89(25.6)$ & $16(34)$ \\
\hline Uncertain outcome & $141(39.7)$ & $16(33.3)$ \\
\hline Non-evaluation & $89(25.1)$ & $16(33.3)$ \\
\hline
\end{tabular}

\section{Result (2)}

$>\quad$ The health professionals working as a DE were outpatient nurses $(84.1 \%)$, nutritionists (59.8\%), pharmacists (53.6\%), doctors (44.7\%), inpatient nurses (34.2\%), physical therapists $(18.4 \%)$, health educators (15.1\%), Thai traditional medicine staffs (7.7\%) and dentists (3.2\%). DEs self-reported the percentage $\pm S D$ of patients receiving diabetes education in $<30,31-60,61-120,121-500$ and $>500$ beds hospitals were $70 \pm 23,73 \pm 21,62 \pm 26,63 \pm 26$ and $46 \pm 27$, respectively.

Table 2. Perceptions of barriers to diabetes education among different groups of respondents in public hospitals

\begin{tabular}{lrrr} 
& Administrators & Doctors & DEs \\
& $(n=264)$ & $(n=269)$ & $(n=355)$ \\
\hline $\begin{array}{l}\text { Non-compliance with } \\
\text { recommended changes of } \\
\text { unhealthy behavior }\end{array}$ & $217(82.2)$ & $220(81.8)$ & $299(84.2)$ \\
\hline Lack of time for diabetes & $205(77.7)$ & $186(69.1)$ & $303(85.4)^{*+}$
\end{tabular}

education by DEs due to other

duties

Lack of interest in diabetes $\quad 195(73.9) \quad 207(77) \quad 275(77.5)$

education from patients

Lack of skill of DEs in assisting

$151(57.2) \quad 108(40.1) \quad 219(61.7)^{\dagger}$

patients with behavioral change

Inadequate numbers of DEs

$115(43.6) \quad 118(43.9) 203(57.2)^{*+}$

$\begin{array}{llll}\text { Lack of suitable place to provide } & 90(34.1) & 71(26.4) & 184(51.8)^{* \dagger}\end{array}$

diabetes education

Lack of budget to support effective $64(24.2) \quad 61(22.7) \quad 106(29.9) \dagger$

diabetes education

$\begin{array}{llll}\text { Lack of suitable educational } & 53(20.1) & 42(15.2) & 147(41.4)^{*+}\end{array}$

material

Data are presented as $n(\%) . \quad{ }^{*} p<0.05$ comparing between administrators and DEs,

$+p<0.05$ comparing between doctors and DEs1

\section{Discussion}

$>\quad$ The majority of the hospitals reported $>60 \%$ of patients received diabetes education. Nevertheless, only $30 \%$ of DEs believed their diabetes education was successful while $60 \%$ of DEs were uncertain about their educational outcomes. Lack of evaluation after education was a diabetes education weakness in Thailand.

$>\quad$ Furthermore, we observed that administrators and doctors tended to report a lower percentage of barriers than DEs. This difference in perception might be another obstacle to diabetes education in Thailand. Therefore, improvements in human resource, educational approach and clear educational role definitions for DEs are needed.

\section{Acknowledgement}

This study is supported by Siriraj Research Development Fund (Managed by Routine to Research : R2R) Faculty of Medicine, Siriraj Hospital, Mahidol University, Thailand. 